Revista Destaques Acadêmicos, Lajeado, v. 10, n. 1, 2018. ISSN 2176-3070

DOI: http://dx.doi.org/10.22410/issn.2176-3070.v10i1a2018.1546 http://www.univates.br/revistas

\title{
A PERCEPÇÃO DOS COLABORADORES E GESTORES DE UMA AGÊNCIA DE UMA INSTITUIÇÃO FINANCEIRA LOCALIZADA NO INTERIOR DO RIO GRANDE DO SUL QUANTO À APLICAÇÃO DE FEEDBACK
}

\author{
Michelle Bayer Leonhardt Castro ${ }^{1}$, Evania Schneider ${ }^{2}$
}

\begin{abstract}
Resumo: Uma preocupação presente na rotina das empresas está ligada com a retenção de seus colaboradores. Vistos como peças chave para o sucesso organizacional, elas estão progressivamente incluindo como prática gerencial a manutenção de uma comunicação mais próxima entre líderes e liderados, sendo o feedback uma das formas utilizadas para essa finalidade. Este estudo tem por objetivo identificar a percepção dos colaboradores e dos gestores de uma agência de uma Instituição Financeira localizada no interior do Rio Grande do Sul quanto à aplicação de feedback, realizando comparações entre a percepção dos colaboradores das duas áreas existentes na agência, bem como com a geração a que pertencem. A metodologia utilizada foi a abordagem qualitativa, sendo o estudo classificado como descritivo e exploratório. A pesquisa identificou que a agência possui um grupo de colaboradores preocupados com seu desempenho, considerando o feedback uma importante ferramenta de comunicação que aproxima gestores e colaboradores. Esse fator demonstra de maneira positiva que o feedback deve ser mantido e aprimorado na agência. Percebeu-se, ainda, que existem opiniões divergentes acerca do formato de execução do feedback, fator que demonstra a necessidade de um bom preparo por parte dos gestores para personalizar sua forma de abordagem junto aos seus colaboradores no momento do feedback.
\end{abstract}

Palavras-chave: Comunicação organizacional. Feedback. Gerações.

\section{INTRODUÇÃO}

É percebido que, de maneira geral, as novas gerações de profissionais que estão se inserindo no mercado de trabalho buscam sempre seu aprimoramento

1 Graduada em Administração de Empresas pela Universidade do Vale do Taquari - Univates e acadêmica do curso de Pós-Graduação em Gestão Estratégica de Pessoas da Universidade do Vale do Taquari - Univates. E-mail: chelly.bayer@gmail.com

2 Bacharela em Administração de Empresas e Ciências Contábeis, especialista em Gestão de Pessoas e Gestão Universitária e mestra em Administração. Email: evania@univates.br 
e, portanto, é fundamental que exista alguma forma de auxílio e orientação ao longo desse processo. Buscando muito além do simples retorno financeiro, elas esperam que seu trabalho seja reconhecido, valorizado e orientado constantemente, podendo esse processo ser realizado através de comentários informais, reuniões de acompanhamento programadas ou relatórios de desempenho escritos. É visto, desse modo, que existem diferentes formas de comunicação disponíveis, devendo as organizações perceber e adotar o método mais adequado às distintas gerações de profissionais que nela se encontram.

Em encontro a essa afirmação, o feedback é uma das técnicas de comunicação utilizada pelas empresas para auxiliar seus profissionais a reconhecer de forma mais clara suas qualidades e oportunidades de melhoria. A aplicação de feedbacks nas organizações tem se demonstrado como uma tendência crescente, uma vez que as novas gerações de colaboradores estão cada vez mais preocupadas em receber um retorno acerca de seu desempenho profissional. É igualmente percebido que a falta de sua utilização possui efeitos negativos, traduzindo-se em profissionais desmotivados e desinteressados com seu desenvolvimento pessoal, o que consequentemente conduz as empresas a ter perdas de qualidade e produtividade.

Preocupada com essa realidade, a partir de 2012, a Instituição Financeira em estudo, situada no interior do Rio Grande do Sul, adotou como prática em sua avaliação de desempenho a utilização de feedbacks formais em momentos programados ao longo de cada ano. Apesar dessa ação, o resultado da última pesquisa de clima realizada em 2016 na Instituição demonstrou que um dos indicadores com menor favorabilidade é justamente relacionado com sua aplicação. Sendo assim, este estudo possui como objetivo identificar a percepção dos colaboradores e dos gestores de uma agência de uma Instituição Financeira localizada no interior do Rio Grande do Sul quanto à aplicação de feedback, comparando-se as repostas dos entrevistados, considerando as respostas das duas áreas existentes na Instituição (administrativa e negocial) e observando as diferentes gerações de colaboradores existentes nesse ambiente de trabalho.

A seguir apresentam-se referenciais relacionados aos assuntos de comunicação organizacional, bem como as características das gerações.

\section{COMUNICAÇÃO ORGANIZACIONAL}

Para Kinicki e Kreitner (2006, p. 301) comunicação é conceituada como "a troca de informações entre um emissor e um receptor, e a inferência (percepção) de significado entre os indivíduos envolvidos". Para Griffin e Moorhead (2006), trata-se de um processo social no qual duas partes trocam informações, e assim proporcionam o compartilhamento de significados. A comunicação interpessoal, por sua vez, tem o objetivo de estabelecer uma associação ou ligação, um entendimento ou uma identificação entre as partes, 
mesmo que momentâneo, visando aproximar-se de alguma forma (OLIVEIRA M., 2010).

Kinicki e Kreitner (2006) afirmam que comunicar não é algo simples nem definido, e que a comunicação apresenta lacunas. Complementam que, reconhecendo esses problemas, os pesquisadores começaram a estudar a área, entendendo que se trata de um processo no qual os receptores da mensagem criam significado em suas mentes. O modelo de comunicação apresentado por Robbins (1999) descreve que antes da comunicação acontecer, é necessário transmitir um objetivo, que passará entre o emissor e o receptor. A mensagem é codificada e passada através de algum meio ao receptor, que decodifica a mensagem iniciada pelo emissor. $O$ resultado desse processo, conforme o autor, é a transferência de significado de uma pessoa para a outra.

Robbins (1999) complementa que a comunicação deve, além de incluir a transferência da mensagem, também gerar a compreensão do significado entre as pessoas. Ele cita que em uma organização, a comunicação tem quatro grandes funções, que são: controle, motivação, expressão emocional e informação.

Uma das funções da comunicação para Robbins (1999) é o controle, pois quando uma empresa exige que os empregados comuniquem logo ao seu superior imediato qualquer ressentimento ligado ao trabalho, ou que sigam as políticas da empresa e a descrição do seu cargo, a comunicação está desempenhando a função de controle. Para o autor, a comunicação também gera motivação, quando o funcionário é esclarecido sobre o que deve ser feito, o que pode fazer para melhorar e o quão bem está desempenhando suas tarefas. Além disso, a comunicação proporciona a expressão emocional dos sentimentos, por permitir que os funcionários interajam socialmente, expondo sua satisfação e suas frustrações (ROBBINS, 1999).

A comunicação entre indivíduos e grupos é vital em todas as organizações (GRIFFIN; MOORHEAD, 2006, p. 188). Para os autores, o principal propósito dela é coordenar as ações das várias partes de uma empresa. Concluem que, sem ela, uma companhia seria uma aglomeração de trabalhadores individuais, realizando tarefas isoladas, resultando em uma ação organizacional descoordenada e orientada apenas para metas individuais.

As empresas, percebendo que a evolução de seu processo de comunicação entre os gestores e os funcionários é de suma importância para o desenvolvimento organizacional, passaram a adotar a técnica do feedback, sendo essa uma das partes integrantes desse processo.

\subsection{Feedback}

O feedback conceitua-se como um retorno ao emissor a respeito de uma mensagem anteriormente emitida por ele (OLIVEIRA M., 2010). Newstrom (2008) complementa que o feedback completa o ciclo de comunicação, pois o receptor reconhece a mensagem e responde ao emissor, sendo um processo de 
duas vias. Para o autor, o emissor precisa receber feedback para indicar que a mensagem foi recebida, decodificada adequadamente, aceita e usada. Esse processo gera grande satisfação, previne frustrações e aprimora a precisão do trabalho (NEWSTROM, 2008).

Dentro do ambiente de trabalho, o feedback é apresentado como uma forma de retorno dado pelos gestores aos seus colaboradores, pois, conforme Newstrom (2008), as pessoas têm necessidade de receber feedbacks sobre seu desempenho, o que irá ajudá-las a se aprimorar e saber o quão bem estão alcançando suas metas. Oliveira M. (2010) complementa que dar um bom feedback consiste em descrever o comportamento do outro sem julgá-lo, pois o principal objetivo dessa ferramenta de comunicação deve ser ajudar os funcionários a tomar conhecimento sobre seu comportamento ou desempenho sobre algo que muitas vezes eles próprios ainda não perceberam.

O feedback também deve ser usado para reforçar comportamentos positivos e para elevar ou manter a autoconfiança e autoestima dos colaboradores (OLIVEIRA, M., 2010). O autor reforça que o feedback é um instrumento usado para estabelecer ou reforçar uma relação de confiança entre gestores e colaboradores, rompendo barreiras no relacionamento interpessoal.

Apesar de apresentar vantagens, a real utilização do feedback é um desafio para muitos gerentes. Muitos deles falham, pois sentem-se muito ocupados, acreditam que seus funcionários já estão cientes do seu desempenho ou tem receio das possíveis reações negativas que podem surgir ao aplicar feedbacks corretivos. Dessa forma, o feedback acaba não ocorrendo ou, quando aplicado, é realizado de forma superficial (NEWSTROM, 2008).

Entretanto, o feedback se apresenta como um meio efetivo para esclarecer os colaboradores sobre os pontos a serem trabalhados e as qualidades e deficiências na execução do trabalho. Ele pode gerar novas formas de condução do trabalho e gerar mudanças, é eficaz na modificação de atitudes inadequadas e é também uma ótima ferramenta para reforçar comportamentos apropriados e atitudes criativas e inovadoras por parte dos funcionários (OLIVEIRA, M., 2010). Por fim, Newstrom (2008) reitera que o feedback melhora a autoimagem e o sentimento de competência do funcionário, levando-o a um melhor desempenho e melhores atitudes, pois através dele o gestor demonstra que está interessado no que o colaborador está fazendo.

De acordo com as colaborações de Newstrom (2008), o feedback deve estar focado nos comportamentos específicos do trabalho, baseando-se em dados objetivos e não em opiniões ou questões subjetivas. Ele acrescenta que o retorno do desempenho tem capacidade de induzir uma mudança de comportamento se for desejado pelo funcionário e se estiver conectado às atividades do trabalho. Para tal realidade, é importante que os gestores tenham um conhecimento mais aprofundado de suas equipes de trabalho, percebendo as características das diferentes gerações de profissionais existentes nas organizações. 


\section{CARACTERÍSTICAS DAS GERAÇÕES}

Para Mannheim (1993), uma geração é formada por indivíduos que vivenciaram fatos históricos ou eventos de grande importância durante o seu processo de socialização. Conforme o autor, essas experiências em comum fizeram com que essas pessoas processassem os acontecimentos de maneira semelhante, moldando a sua forma de pensar ao longo da vida e seus valores. Veloso, Silva e Dutra (2011) citam que embora seja essencial considerar as diferenças de cada ser humano, é possível considerar que as pessoas de uma mesma geração compartilhem desejos, expectativas e percepções sobre as organizações e sobre o trabalho em suas vidas.

Ao longo dos anos, eventos de grande impacto histórico e as vivências das pessoas auxiliaram para a configuração das diferentes gerações, as quais serão apresentadas no Quadro 1, para destacar suas principais características e diferenças.

Quadro 1 - Características das gerações

\begin{tabular}{|c|c|c|c|}
\hline $\begin{array}{c}\text { Baby Boomers } \\
(1946-1960)\end{array}$ & $\begin{array}{c}\text { Geração X } \\
(1960 \text { - 1980) }\end{array}$ & $\begin{array}{c}\text { Geração } Y \\
(1980 \text { - 1990) }\end{array}$ & $\begin{array}{c}\text { Geração Z } \\
(1990 \text { - 2010) }\end{array}$ \\
\hline $\begin{array}{l}\text { - Valorizam a } \\
\text { segurança e a } \\
\text { estabilidade no } \\
\text { trabalho; } \\
\text { - São leais e } \\
\text { apegados às } \\
\text { empresas; } \\
\text { - Interessados } \\
\text { pela aquisição de } \\
\text { status e poder ao } \\
\text { longo da carreira; } \\
\text { - Respeitam a } \\
\text { hierarquia e } \\
\text { valorizam as } \\
\text { autoridades e a } \\
\text { disciplina; } \\
\text { - Possuem mais } \\
\text { dificuldades para } \\
\text { equilibrar a vida } \\
\text { profissional e } \\
\text { pessoal. }\end{array}$ & $\begin{array}{l}\text { - Considerados mais } \\
\text { individualistas e } \\
\text { mais interessados } \\
\text { em ganhos de } \\
\text { oportunidade; } \\
\text { - São menos leais às } \\
\text { organizações e com } \\
\text { maior tendência } \\
\text { para buscar novos } \\
\text { desafios e melhores } \\
\text { recompensas; } \\
\text { - São menos suscetíveis } \\
\text { a liderança formal e } \\
\text { mais adaptáveis às } \\
\text { mudanças; } \\
\text { - Têm maior } \\
\text { necessidade de } \\
\text { feedback; } \\
\text { Buscam maior } \\
\text { equilíbrio entre a vida } \\
\text { pessoal e profissional. }\end{array}$ & $\begin{array}{l}\text { - Possuem facilidade } \\
\text { de aprendizado, } \\
\text { têm muitas ideias } \\
\text { e disposição para } \\
\text { realizá-las; } \\
\text { - São ambiciosos, } \\
\text { e sentem a } \\
\text { necessidade de } \\
\text { ter oportunidades } \\
\text { de crescimento } \\
\text { e desafios } \\
\text { constantes; } \\
\text { - Esperam receber } \\
\text { feedbacks } \\
\text { constantes e } \\
\text { reconhecimento } \\
\text { acerca do seu } \\
\text { desempenho; } \\
\text { - Exigem chefes } \\
\text { presentes e que } \\
\text { acompanhem o seu } \\
\text { desenvolvimento. }\end{array}$ & $\begin{array}{l}\text { - Nasceu sob o } \\
\text { advento da internet e } \\
\text { das tecnologias; } \\
\text { - São considerados } \\
\text { multitarefas, } \\
\text { multiconectados, } \\
\text { multiestimulados e } \\
\text { multinformados; } \\
\text { - São desapegados } \\
\text { das fronteiras } \\
\text { geográficas; } \\
\text { - Menos propensos } \\
\text { a reflexão e mais } \\
\text { impacientes; } \\
\text { - São individualistas e } \\
\text { têm dificuldades de } \\
\text { trabalhar em equipe; } \\
\text { - São mais } \\
\text { independentes e com } \\
\text { dificuldades para } \\
\text { serem contrariados e } \\
\text { dividir. }\end{array}$ \\
\hline
\end{tabular}

Fonte: elaborado pela autora com base em Cavazotte, Lemos e Viana (2012); Grassi, Andrade e Veloso (2016); Lombardia (2008); Missel (2012); Oliveira (2012); Oliveira S. (2010).

O próximo item descreve os procedimentos metodológicos utilizados no estudo, visando atender aos objetivos propostos. 


\section{MÉTODO}

A agência em estudo localiza-se em uma cidade do interior do Rio Grande do Sul, possui 24 colaboradores e dois gestores, divididos em duas áreas de atuação: administrativa e negocial.

Este estudo possui caráter qualitativo. A pesquisa qualitativa pode ser definida como uma "pesquisa não-estruturada e exploratória, baseada em pequenas amostras que proporciona percepções e compreensão do contexto do problema" (MALHOTRA, 2006, p. 155). A escolha pela pesquisa qualitativa para esse estudo deu-se em função de buscar uma análise mais aprofundada e com mais detalhes acerca da percepção dos colaboradores e dos gestores da agência.

Quanto aos objetivos, este estudo é descritivo e exploratório. Conforme Malhotra (2006), a pesquisa descritiva possui o principal objetivo de descrever algo. Vergara (2014) complementa que ela expõe as características de determinada população ou fenômeno. Portanto, este estudo é assim classificado, pois visou descrever a percepção dos colaboradores e dos gestores da agência em estudo.

A pesquisa exploratória tem o objetivo de auxiliar o pesquisador a compreender melhor a situação-problema por ele enfrentada (MALHOTRA, 2006). O mesmo autor compreende que esse tipo de pesquisa é utilizado quando é necessário definir o problema com maior precisão, identificar possibilidades de ação ou obter dados adicionais antes de desenvolver uma abordagem. Gil (2010) afirma que se trata de um período de investigação no qual o pesquisador procura obter o entendimento dos fatores que exercem influência na situação que constitui o objeto de pesquisa. Neste estudo, a etapa exploratória foi utilizada para permitir à pesquisadora maior aprofundamento sobre o tema.

O questionário foi elaborado com base no referencial teórico deste estudo, onde para os colaboradores foram desenvolvidas duas questões objetivas visando identificar seu perfil e sete questões subjetivas, voltadas à percepção da realização do feedback. Para os gestores, foi realizada uma questão objetiva para identificação do perfil e sete questões subjetivas, que objetivaram identificar a percepção destes acerca do tema. O pré-teste foi realizado com dois colaboradores, e após a validação, os questionários foram enviados aos respondentes.

As questões foram encaminhadas através da ferramenta "Formulários do Google", objetivando o maior número de respondentes e para preservar o anonimato, de forma que a pesquisadora não identificasse os entrevistados. $\mathrm{O}$ convite de participação da pesquisa foi enviado por e-mail no dia 04/07/2017, solicitando as respostas até o dia 19/07/2017. Dos 24 colaboradores, a pesquisa foi enviada a 23 deles, uma vez que a pesquisadora faz parte da equipe. Dos 23 questionários enviados, 20 foram respondidos, bem como os questionários dos dois gestores da agência. 
Após o recebimento dos questionários, realizou-se a interpretação das respostas, sendo que as questões subjetivas foram analisadas através da análise de conteúdo, e as questões objetivas foram tabuladas e transcritas de acordo com o perfil dos respondentes.

\section{ANÁLISE DOS RESULTADOS DA PESQUISA}

Este capítulo apresenta a análise dos resultados da pesquisa. Buscouse, com as questões iniciais, identificar o perfil dos respondentes no que se refere à idade e a área em que atuam na agência em estudo. Os resultados das respectivas questões serão apresentados nos a seguir.

Inicialmente, foram analisadas as respostas dos colaboradores, em seguida dos gestores e, posteriormente, foram realizadas comparações entre as respostas obtidas com os dois grupos de entrevistados. Além disso, foram observadas as características das respostas dadas pelas diferentes gerações de colaboradores existentes na agência, e de acordo com as áreas em que eles atuam.

\subsection{Análise do perfil dos colaboradores}

Segundo a classificação das gerações proposta por Lombardia (2008), a agência em estudo possui 85\% de colaboradores da Geração Y (27 a 37 anos), representados por 17 respondentes; dois colaboradores pertencem à Geração Z, possuindo até 26 anos, representando $10 \%$ dos entrevistados; um colaborador pertence à Geração Baby Boomer (mais de 53 anos de idade), representando 5\% dos respondentes. Nenhum colaborador pertence à Geração X (38 a 52 anos de idade).

Dos 20 colaboradores entrevistados, 55\% atuam na área de negócios e $45 \%$ atuam na área administrativa, representados por 11 e nove colaboradores, respectivamente.

Após identificar o perfil dos colaboradores entrevistados, serão apresentados os resultados das questões subjetivas, as quais objetivaram detalhar as percepções dos respondentes acerca do recebimento de feedback.

\subsection{Análise das entrevistas}

Quando questionados sobre o que compreendem por feedback, 13 dos 20 colaboradores citaram que consideram esse como um "retorno do gestor acerca do desempenho", cinco entendem como uma "conversa" entre gestores e colaboradores e oito apresentaram em suas respostas que o feedback é entendido como um momento para análise dos "pontos fortes e fracos, bem como como oportunidades de melhoria". Também foram apresentadas nas respostas expressões como "incentivo ao desenvolvimento", "elogio sobre o trabalho realizado" e "orientação e direção ao aprimoramento". Para Missel 
(2012) a correta aplicação das técnicas de feedback permite duradouras mudanças de comportamento, compatíveis com a velocidade exigida pelo mercado.

Em relação à importância atribuída a realização de feedback por parte do gestor, praticamente todos os colaboradores (90\%) utilizaram em suas respostas termos semelhantes, apontando que a realização do feedback é importante ou muito importante. 13 respondentes avaliam que a realização dos feedbacks é muito importante, representando $65 \%$ dos 20 entrevistados. Cinco colaboradores, por sua vez, avaliam a realização do feedback como importante, representando $25 \%$ das respostas. Os outros dois respondentes $(10 \%)$ não mencionaram um grau de importância para realização do feedback, no entanto ambos utilizaram expressões que demonstraram acreditar na importância do feedback, como "gosto muito desse retorno pois é uma forma de saber como estou sendo visto pela empresa", e "acredito que auxilia no crescimento profissional do colaborador".

Entre os principais motivos apresentados pelos entrevistados para reforçar a importância da realização de feedback, destacam-se que ele auxilia os profissionais a: ver se eles estão agindo de forma correta, saber o que precisam melhorar, mostrar como seguir na carreira profissional, refletir sobre suas atitudes, ter clareza sobre a produtividade no trabalho, reconhecer o esforço realizado e identificar dificuldades a superar.

Para Matos (2015), quando o feedback é realizado e as pessoas conseguem ouvir e ser ouvidas, e expor seus pensamentos e sentimentos, todo saem ganhando, pois se sentirão motivados, considerados e respeitados, buscando melhores resultados em suas atividades.

A quinta questão buscou identificar qual a percepção dos colaboradores quanto ao momento mais adequado para a realização do feedback, sendo que os resultados estão demonstrados no Gráfico 1. 
Gráfico 1 - Momento mais adequado para a realização do feedback

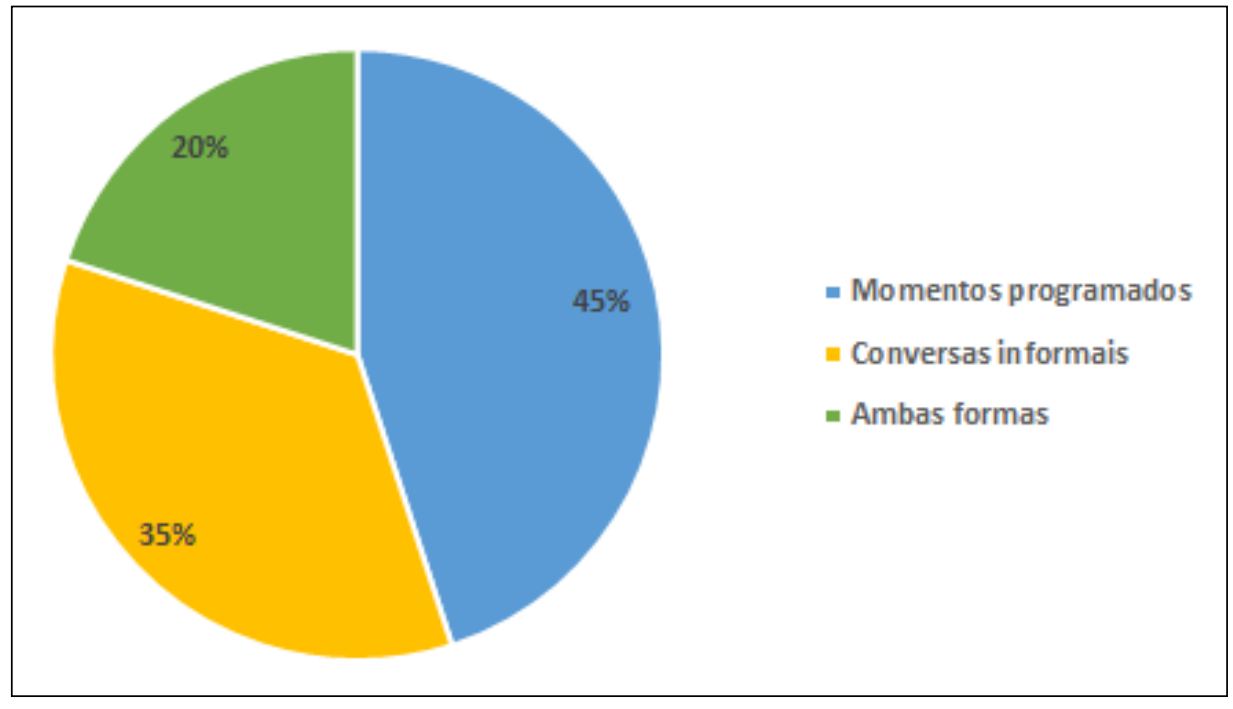

Fonte: elaborado pela autora (2017).

Diferentemente das questões anteriores, percebe-se uma disparidade de opiniões quanto ao momento mais adequado para a realização do feedback, pois $45 \%$ dos respondentes prefere que ele seja realizado em momentos programados. Esses nove colaboradores afirmaram como principais motivos dessa escolha o fato de permitir "ciência do assunto com antecedência", "se for apenas informal pode não acontecer", "se for somente informal pode dar-se ênfase a casos isolados, perdendo o foco", e sendo informal "pode que alguém fique de fora".

Já 35\% dos respondentes prefere que o feedback seja realizado em conversas informais. Os sete colaboradores que afirmaram preferir essa forma de abordagem, justificaram que "se for programado acaba sendo simplesmente para preencher tabelas e se for informal é feito de coração e quando necessário", a conversa informal "permite que as coisas sejam resolvidas assim que elas ocorrem", e "quando for inesperado traz muita motivação". Quatro colaboradores acreditam que o feedback deve ocorrer de ambas formas, representando 20\%. Destaca-se um dos entrevistados que acredita que "feedbacks podem ser realizados das duas formas, com conversas informais ou com horas programadas para tal, desde que o colaborador tenha ciência de que está recebendo um feedback".

Missel (2012) aconselha que diminuir o intervalo de acontecimento do feedback é benéfico, pois possibilita ao funcionário a correção das suas atitudes com maior brevidade, pois os detalhes do fato ocorrido estarão bem presentes na memória. 
A próxima questão solicitada aos colaboradores teve por objetivo entender de que forma o feedback impacta no seu desempenho no trabalho. Muitos respondentes concordam que o feedback pode oferecer impactos tanto positivos quanto negativos, afetando significativamente a sua motivação. Um dos entrevistados relatou que "o feedback é um norte para a realização do nosso trabalho, porém a forma como as situações muitas vezes são apresentadas, desmotivam o colaborador". Outro respondente complementa a afirmativa, constatando que "tudo depende da capacidade de motivação que o gestor passa para o liderado, independente do feedback ser positivo ou negativo".

Alguns entrevistados, por sua vez, percebem o feedback como um direcionador para melhorar o desempenho, propiciando mais segurança ao funcionário e fazendo com que os objetivos individuais estejam em consonância com os da organização.

Uma das questões buscou verificar se os colaboradores entendem que o feedback aproxima-os dos gestores. Foi possível constatar que todos os colaboradores acreditam que o feedback aproxima-os de seus gestores, alegando que essa forma de comunicação demonstra interesse por parte do gestor no crescimento do colaborador, estabelece uma relação de confiança e respeito, permite com que um conheça o perfil do outro e faz com que o gestor preste mais atenção e pense a respeito do colaborador, fazendo com que o funcionário se sinta percebido e valorizado. Um dos colaboradores observou que "antes de mais nada o feedback deve ser realizado de forma correta. Se o gestor não apresentar a competência necessária para desenvolver um feedback, este pode tornar-se num verdadeiro problema ao invés de uma solução. Caso este for conduzido de uma forma apropriada, a relação de gestor e colaborador tornarse cada vez mais sinérgica e o resultado da equipe tende a ser satisfatório".

Para Matos (2015), a abertura para o diálogo e a comunicação são os principais pontos para manter relacionamentos duradouros e produtivos, sendo que o principal objetivo da comunicação é criar conexão entre as pessoas. Para ele, esse elo entre as pessoas favorece a conquista de metas, a superação de problemas e a visualização de novas oportunidades.

Quando questionados acerca dos resultados do feedback na melhoria do desempenho, grande parte dos colaboradores percebe que o feedback recebido os auxiliou a melhorar o seu desempenho. Como aspectos mais evidenciados nas respostas, destacam-se: a melhoria no desempenho e nas atitudes, citada por nove entrevistados, aumento na motivação, lembrada por três respondentes. Um funcionário da agência relatou que: "Percebo que o feedback poderia ser mais trabalhado. São momentos de conversar sobre o lado profissional, o pessoal e oportunidades para o colaborador. Acredito que trazer somente à tona as situações e não apresentar uma oportunidade de melhoria não tem serventia. Acredito que falta um pouco de preparo para dar retorno de feedback e como tratar algumas situações. Tem situações que devem ser tratadas no momento que acontecem e outras que podem aguardar o feedback 
para conversar. Quando recebo meu feedback, primeiro tenho que digerir tudo que é dito, pois às vezes é difícil entender o que o gestor tem a dizer. A comunicação precisa ser clara".

Matos (2015) afirma que o feedback deve promover a mudança de atitudes, pensamentos e comportamentos, buscando informar a pessoa de que forma a sua atuação está afetando outras pessoas ou situações. Para ele, o feedback eficaz deve ser capaz de auxiliar os funcionários a melhorar seu desempenho.

A última questão da entrevista buscou identificar a visão dos colaboradores acerca do auxílio do feedback na retenção de pessoas nas organizações, obtendo-se as respostas demonstradas no Gráfico 2.

Gráfico 2 - Você acredita que o recebimento de feedback por parte do gestor é um fator que contribui para a retenção de pessoas nas organizações?

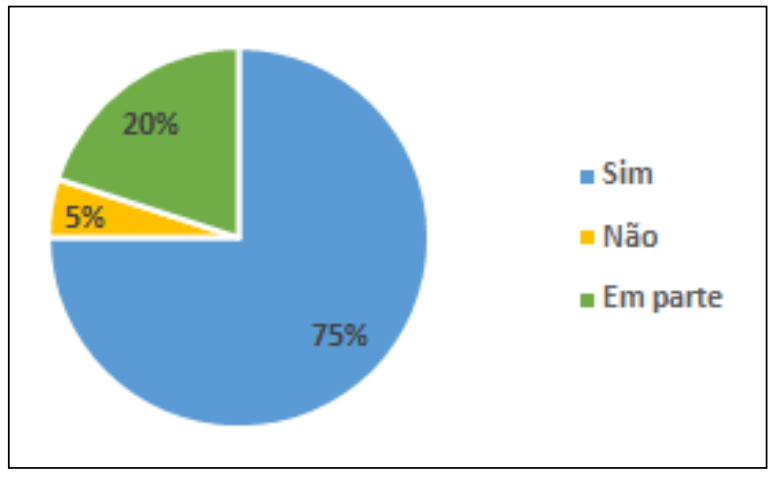

Fonte: elaborado pela autora (2017).

Pode-se perceber no Gráfico 2 que a maioria dos respondentes acredita que o feedback contribui para a retenção de pessoas nas organizações, representados por 15 colaboradores, que totalizam $75 \%$. Quatro colaboradores acreditam em parte, representando $20 \%$ dos entrevistados. Eles alegam que quando o feedback é feito por pessoas competentes e de forma clara e justa, é motivo para que o colaborador permanecer na empresa. Porém, quando é feito de "qualquer jeito", somente por questão de formalização, não tornase um fator relevante para a retenção de funcionários. Um colaborador (5\%) afirmou que não acredita que o feedback auxilia na retenção de pessoas nas organizações.

Para Missel (2012), mais difícil do que atrair novos profissionais, é manter os melhores na empresa, pois esses estão atentos a sua empregabilidade e seu futuro profissional. Para ela, os gestores que não se preocuparem em desenvolver e reter os jovens talentos, revisando suas políticas de gestão e criando estratégias para a permanência desses, terão grande dificuldade de 
reposicionamento e competitividade no mercado atual. Ela citou estratégias para a retenção de talentos, e dentre elas encontram-se: reuniões de feedback constantes; programas de acompanhamento realizados pela gerência imediata, e não pelo setor de recursos humanos; reconhecimento e valorização direta do trabalho; e possibilidade de ascensão profissional.

A agência em estudo possui dois gestores, sendo um mais voltado para a área negocial e outro para a área administrativa. As respostas a seguir foram concedidas pelos gestores, demonstrando quais as suas percepções acerca do tema feedback.

Quando questionados sobre o que entendem por feedback, um dos gestores afirmou que "é uma ferramenta/técnica para manter e aumentar o engajamento e produtividade, mediante análise e desenvolvimento de competências pessoais". Já o outro gestor entende como um "momento entre gestor e colaborador, onde ocorre a análise de fatos ocorridos no ambiente de trabalho, com o objetivo de melhorar o desempenho do colaborador através da manutenção ou mudança de sua conduta".

A segunda questão direcionada aos gestores buscou entender a visão dos mesmos acerca dos benefícios obtidos ao realizar feedback, tanto para eles quanto para os seus colaboradores.

Como principais colocações, os gestores alegaram que a realização do feedback "favorece a proximidade dos colaboradores", ao passo que eles conseguem analisar individualmente as competências dos colaboradores a fim de desenvolver em conjunto as "potencialidades e tratar situações desfavoráveis de maneira mais produtiva e assertiva". Além disso, os gestores afirmaram que "através dele que os colaboradores podem direcionar seus esforços para um possível alinhamento ou manutenção de suas condutas, com foco no desenvolvimento de suas carreiras".

Em relação aos benefícios obtidos para os gestores, esses comentaram que a realização do feedback lhes oferece importantes vantagens, tais como uma "equipe mais alinhada às boas práticas disseminadas pelo gestor, equipe mais confiante e com melhor desempenho e consequentemente alcançado os resultados desejados pela Instituição". Ambos gestores destacaram em seus relatos que a realização dos feedbacks torna os colaboradores mais confiantes e tranquilos, uma vez que os mesmos estarão sendo avaliados com objetivos e um sistema de avaliação mais claros.

Questionados acerca do momento para realização do feedback, os gestores transmitiram respostas complementares, mas que de certo modo possuem características distintas. Um deles acredita que o feedback deve ocorrer em momentos programados, uma vez que assim eles irão reservar um tempo de suas agendas para concentrar seus esforços junto a seus colaboradores, para então avaliar conjuntamente o desenvolvimento individual dos mesmos. Ao mesmo tempo, esse gestor defende que as conversas informais também 
possuem vantagens, visto que elogios pontuais e sem formalidades servem como grandes motivadores, assim como a realização de ações corretivas quando necessário. Tratadas de imediato, elas servem como mecanismo para realinhar os colaboradores a "um foco mais assertivo e produtivo".

O segundo gestor entrevistado, por sua vez, considera que mais importante do que a escolha do momento para realização do feedback é o conhecimento da equipe de profissionais com a qual se está trabalhando, uma vez que, segundo ele, "existem equipes que são mais auto gerenciáveis e preferem feedbacks informais e curtos, mas dentro desta mesma equipe podem existir perfis que preferem o feedback formal". Desse modo, ele defende que o melhor formato para realização de um feedback varia muito de acordo com a equipe de trabalho, devendo o gestor ter a habilidade de conhecer as características de seu grupo e então escolher a melhor forma de aplicá-lo.

Missel (2012) aconselha que os resultados do feedback são mais produtivos se forem fornecidos no menor tempo possível depois de um fato ter ocorrido, de preferência no momento que a situação ocorre, ou no máximo em até 24 horas depois. Ela complementa que é comum os gestores terem dificuldades para acompanhar a rotina dos seus funcionários, devido ao volume de atividades, por terem equipes muito grandes, ou pela distância física. Afirma, no entanto, que o líder precisa encontrar maneiras de superar essas barreiras, evitando a queda nos resultados da equipe e a lentidão no desenvolvimento e na capacitação dos profissionais.

Quando questionados acerca do impacto do feedback no desempenho dos colaboradores, um dos gestores afirmou que ele é positivo, pois "sabendo do que se espera do nosso desempenho, auxilia muito a manter o foco e ser mais produtivo e engajado". O outro gestor complementou que o feedback pode oferecer impactos positivos ou negativos, alertando que "quando mal aplicado, traz consequências tais como a falta de comprometimento, o desânimo, etc". Robbins e Judge (2014) complementam que as pessoas apresentam melhoras significativas quando recebem um feedback de como estão progredindo, pois ele ajuda a identificar a discrepância entre o que está sendo realizado e o que foi combinado, sendo um direcionador de comportamento.

A quinta questão aplicada aos gestores objetivou verificar suas percepções acerca da relação entre a realização do feedback e a aproximação obtida entre eles e seus colaboradores subordinados.

Como respostas, os gestores apontaram que a realização de feedbacks bem estruturados possui efeitos muito positivos no que tange a aproximação entre gestores e colaboradores. Um dos gestores relatou que o feedback "trabalha muito o relacionamento gestor $\mathrm{x}$ colaborador nestas conversas, todos precisam estar "abertos" para elogios e críticas, e a partir da exposição de expectativas de ambos é que conseguimos construir algo em conjunto". O outro gestor, por sua vez, concordou que o feedback pode aproximar as duas partes 
envolvidas, entretanto ele alertou que o feedback, quando mal aplicado, "afasta ainda mais o colaborador do seu gestor".

Questionados sobre as mudanças no comportamento e desempenho individual dos colaboradores a partir da realização do feedback, ambos gestores concordaram que o relacionamento entre eles e os colaboradores torna-se mais próximo, criando-se um laço de confiança mútua e troca de informações entre as partes. Eles ainda afirmaram que o feedback "favorece muito também o clima de trabalho, cada um sabendo do seu desempenho e expectativa", além de aproximar os objetivos dos líderes e liderados, ao afirmarem que os colaboradores têm seus supervisores como "parceiros em suas ações, que são combinadas e referendadas por eles."

Para Kyrillos e Jung (2015), o líder não deve utilizar o feedback para criticar, ma sim para ajudar a construir as pessoas, fornecendo feedback com foco no desenvolvimento. Para eles, o olhar diferenciado sobre essa prática é decisivo no resultado que o líder pode obter junto aos seus colaboradores, pois a atitude de quem fala influencia a atitude de quem ouve, promovendo então a ação.

A última questão respondida pelos gestores buscou verificar suas opiniões acerca do feedback ser utilizado pelas organizações como meio para retenção de talentos. Como respostas, obtiveram-se opiniões complementares. Um dos gestores foi mais enfático ao afirmar que "muitas vezes uma boa conversa sincera e apoio são fatores determinantes para manter um clima de trabalho positivo e de inclusão", em uma relação em que o "colaborador que possui apoio do seu gestor, e gestor que possui a confiança dos seus colaboradores, com toda a certeza conseguem gerir melhor sua relação trabalhista a fim de manterem-se motivados e certamente isto será ponto decisivo em permanecer ou não em uma organização".

O segundo gestor entrevistado observou que apenas a realização do feedback não pode ser considerado um fator determinante para manter os colaboradores, mas sim um complemento que deve fazer parte de outros programas das organizações, tais como a "Cultura Organizacional, Clima Organizacional (feedback faz parte), Remuneração, Possibilidade de Desenvolvimento (plano de carreira) que também são fundamentais para a retenção".

A retenção de talentos tornou-se uma "arte no mundo corporativo. Os líderes que souberem mantê-los em suas equipes e resistirem às propostas de trabalho que eles podem receber da concorrência estarão no céu" (MISSEL, 2012, p. 72). Para a autora, a pressão por resultados e o estresse do dia a dia fazem com que fique mais difícil para os gestores repensarem o seu posicionamento e a forma de abordarem seus funcionários. Ela sugere que uma maneira de solucionar essa questão seria o líder pedir aos seus colaboradores um feedback sobre como eles estão percebendo a qualidade e a quantidade de seus retornos, 
questionando-os se eles estão sendo suficientes para que se sintam reconhecidos, motivados e comprometidos com seu trabalho e com a empresa.

Tendo sido realizadas as entrevistas com os colaboradores e gestores da agência, buscou-se também realizar comparações entre as respostas de acordo com a área em que esses atuam, bem como verificar se existem percepções divergentes sobre o feedback de acordo com as diferentes gerações dos colaboradores. Não sendo possível apresentar comparativos para todas as questões aplicadas, optou-se por destacar aquelas que permitiram tais comparações e posteriormente realizar análises com as respostas fornecidas pelos grupos.

\subsection{Comparativos em relação à área em que atuam}

Através dos comparativos realizados entre as respostas dos colaboradores e gestores de acordo com a área em que atuam, pode-se perceber que, em relação ao grau de importância atribuído à realização feedback, tanto a área administrativa quando a área negocial consideram que esse retorno é muito importante. Do mesmo modo, os dois gestores das áreas consideram importante a realização desse momento. Verifica-se, assim, que as percepções dos colaboradores e gestores estão em consonância nesse aspecto.

Já no que se refere à forma de aplicação do feedback, a área administrativa apresenta um alinhamento de percepções ao demonstrar que o gestor e sua equipe preferem que os feedbacks sejam realizados de ambas formas (momentos programados e conversas informais). A área negocial, por sua vez, demonstrou estar dividida, pois seis colaboradores preferem momentos programados para realização do feedback e cinco acreditam que conversas informais são o melhor formato para aplicação do feedback. O gestor dessa área afirmou em suas respostas que os feedbacks devam ser aplicados em ambas formas, o que demonstra que sua visão está em sintonia com a de sua equipe de trabalho.

Em relação ao feedback auxiliar na retenção de profissionais nas empresas, tanto o gestor quanto a maior parte dos colaboradores da área administrativa acreditam que a realização desses momentos contribui com a retenção. Já quase a totalidade da área negocial afirma que o feedback auxilia nesse fator, porém o líder da área concorda em parte com o questionamento, afirmando que o feedback sozinho não promoverá tal retenção, mas sim somado a outros comportamentos, tais como a cultura organizacional, a remuneração, entre outros.

Além da comparação das respostas em função das áreas dos colaboradores da agência, foi realizado o mesmo comparativo de questões organizando os grupos de acordo com as gerações a que esses pertencem. 


\subsection{Comparativos em relação à geração que pertencem}

Iniciando-se as análises a partir das respostas fornecidas pelos colaboradores da Geração Z (até 26 anos de idade), é percebido que os dois colaboradores dessa geração apresentam divergências em suas percepções. Enquanto o primeiro atribui um grau elevado de importância para aplicação do feedback, o outro não deixa muito claro qual o grau de importância por ele atribuído a esse questionamento. Em relação ao formato para realização do feedback, um dos respondentes afirmou que os momentos formais são mais adequados, ao passo que o outro respondeu que os momentos não programados são mais convenientes. Por fim, questionados acerca do feedback auxiliar para retenção dos profissionais nas empresas, um dos respondentes concordou com essa afirmação e o outro discordou.

Torna-se importante destacar que a pesquisa realizada não apresentou diferenças significativas entre as três gerações entrevistadas. Um dos principais fatores desse comportamento está associado ao baixo número de representantes das Gerações Z (dois colaboradores) e Baby Boomers (um colaborador) em relação aos colaboradores da Geração Y, predominantes na agência.

Desse modo, tornou-se mais valioso para o trabalho de pesquisa entender melhor a equipe de trabalho como um todo, identificando quais são suas percepções acerca da realização do feedback por parte de seus gestores imediatos para então verificar se existe um alinhamento de expectativas entre as duas partes.

\section{CONCLUSÃO}

Uma organização inteligente e preocupada com seu desenvolvimento deve possuir em suas práticas de gestão momentos dedicados para analisar suas ações e projetar estratégias para o futuro, de modo a se manter eficiente e competitiva no mercado. Essa avaliação deve ocorrer tanto em nível estratégico quanto operacional, no qual os trabalhadores são avaliados pelos seus líderes, tendo a liberdade para fazer suas colocações e sugestões de melhoria de seu posto de trabalho ou da própria empresa como um todo. $\mathrm{O}$ feedback vem em encontro a essa afirmação, apresentando-se como uma ferramenta a qual está sendo progressivamente implantada nas empresas, obtendo-se benefícios significativos para os gestores que dedicam parte de seu tempo para comunicarse com sua equipe.

Em relação a agência objeto de estudo da pesquisa, o feedback vêm sendo aplicado há cerca de cinco anos como um dos componentes de suas avaliações de desempenho. Ao longo desse período, já foi percebido um amadurecimento das equipes para absorção e incorporação dessa ferramenta de comunicação dentro do ambiente de trabalho. Através das entrevistas realizadas com gestores e colaboradores, é notado que ambas partes compreendem a importância do feedback, considerando que a realização dos mesmos é muito importante para 
a aproximação e alinhamento de expectativas da empresa e da própria equipe. Além disso, tanto colaboradores quanto gestores das duas áreas (administrativa e negocial) possuem percepções semelhantes acerca do feedback, fator positivo que mostra que ambas partes estão em sinergia.

O que é percebido, no entanto, é que em alguns pontos existem opiniões divergentes quanto a forma de aplicação do feedback. Enquanto uma parcela de $45 \%$ dos colaboradores afirma preferir que o feedback seja realizado em momentos formais, $35 \%$ preferem que seja realizado em momentos não programados e $20 \%$ afirmaram que ambas formas são ideais. Esse fator merece destaque, sendo sugerido para a agência avaliar uma formato misto de execução dos feedbacks, mantendo-se os momentos formais atualmente executados e preparando os gestores para fornecer feedbacks informalmente a seus colaboradores, principalmente aos que demonstrarem preferência por esse tipo de abordagem.

É fundamental, portanto, que os líderes tenham um claro conhecimento de sua equipe de trabalho e das preferências individuais de cada colaborador, definindo junto a esses um formato personalizado de troca de opiniões e informações, o qual trará ainda mais benefícios para todos envolvidos nesse processo. Para que essa realidade seja percebida de forma efetiva dentro da empresa estudada, é fundamental que os líderes estejam bem preparados para avaliar seus colaboradores, para desse modo garantir um maior engajamento desses para o desenvolvimento de toda a agência, visto que a competitividade do mercado tem exigido cada vez mais profissionais qualificados e alinhados aos objetivos organizacionais.

É importante destacar que na agência estudada existe um domínio da geração Y, representada por $85 \%$ dos colaboradores. Essa geração, conforme os autores estudados,é marcada por apresentar um perfil de profissionais preocupados em receber um retorno constante acerca de seu trabalho, seja para elogios pelo bom desempenho ou correção de alguns aspectos ou comportamentos não esperados pela organização. Apresenta-se, assim, mais um ponto de atenção aos gestores da agência, os quais deverão estar preparados para receber um expressivo contingente de profissionais preocupados com seu retorno. Além desse percentual elevado de colaboradores da geração $Y$, as demais gerações estão presentes na organização estudada, devendo assim os líderes ter a habilidade para gerenciar bem esse conjunto de profissionais de diferentes idades, aspirações e opiniões.

Em linhas gerais, conclui-se que o objetivo da pesquisa foi atingido, no qual foram identificadas as percepções dos colaboradores e gestores de uma agência de uma Instituição Financeira localizada no interior do Rio Grande do Sul quanto à aplicação de feedback. Identificou-se, ainda, que tão importante quanto a realização dos feedbacks por parte dos gestores, é imprescindível que eles tenham preocupação com o real entendimento e integração dessa ferramenta de comunicação em seu ambiente de trabalho, aplicando-a de 
acordo com o perfil individual de cada colaborador, pois somente desse modo a realização dos feedbacks terá efetivamente seus benefícios revelados.

\section{REFERÊNCIAS}

CAVAZOTTE, Flavia de Souza Costa Neves. LEMOS, Ana Heloísa da Costa. VIANA, Mila Desouzart de Aquino. Novas gerações no mercado de trabalho: expectativas renovadas ou antigos ideais? Cadernos EBAPE.BR. Rio de Janeiro, v. 10, n.1, artigo 9, mar. 2012. Disponível em: <http://bibliotecadigital.fgv.br/ojs/index.php/ cadernosebape/article/view/5251/3985>. Acesso em 20 jun. 2017.

CHIAVENATO, Idalberto. Gestão de pessoas: o novo papel dos recursos humanos nas organizações. 3. ed. Rio de Janeiro: Elsevier, 2010.

GIL, Antonio Carlos. Gestão de pessoas: enfoque nos papeis profissionais. São Paulo: Atlas, 2001.

GIL, Antonio Carlos. Como elaborar projetos de pesquisa. 5. ed. São Paulo: Atlas, 2010.

GRASSI, José Augusto. ANDRADE, Marcelo Silva de. VELOSO, Elza Fátima Rosa. Gestão de gerações em sistemas bancários. Revista Competitividade e Sustentabilidade - ComSus, Paraná, v.3, n. 1, p. 11-27, jan./jun. 2016. Disponível em: <http:/ /e-revista.unioeste.br/index.php/comsus/article/view/13059/11031>. Acesso em: 7 jul. 2017.

GRIFFIN, Ricky W. MOORHEAD, Gregory. Fundamentos do comportamento organizacional. São Paulo: Ática, 2006.

KINICKI, Angelo. KREITNER, Robert. Comportamento organizacional. 2. ed. São Paulo: McGraw-Hill, 2006.

KYRILLOS, Leny. JUNG, Milton. Comunicar para liderar. São Paulo: Contexto, 2015.

LOMBARDIA, Pilar García. Quem é a geração Y? HSM Management.n.70, p. 1-7. set./out.2008. Disponível em: <https://xa.yimg.com/kq/ groups/17235429/1295339781/.../Quem+é+a+geração+Y.pdf>.Acesso em: 22 jul. 2017.

MALHOTRA, Naresh K. Pesquisa de marketing: uma orientação aplicada. 4. ed. Porto Alegre: Bookman, 2006.

MANNHEIM, Karl. El problema de las generaciones. [tradução: Ignacio Sánchez de La Yncera], REIS - Revista Española de Investigaciones Sociológicas. n. 62, abr-jun1993, p. 193-242. Disponívelem: <http:// www.jstor.org/stable/40183643?seq=1\#page_ scan_tab_contents $>$. Acesso em: 22 jul. 2017. 
MATOS, Gustavo Gomes de. Comunicação aberta: desenvolvendo a cultura do diálogo. São Paulo: Manole, 2015.

MISSEL, Simoni. Feedback corporativo: como saber se está indo bem. São Paulo: Saraiva, 2012.

NEWSTROM, John W. Comportamento organizacional: o comportamento humano no trabalho. São Paulo: McGraw-Hill, 2008.

OLIVEIRA, Marco A. Comportamento organizacional para a gestão de pessoas: como agem a empresa e seus gestores. São Paulo: Saraiva, 2010.

OLIVEIRA, Sidnei. Geração Y: o nascimento de uma nova versão de líderes. São Paulo: Integrare Editora, 2010.

OLIVEIRA, Sidnei. Jovens para sempre: como entender os conflitos de gerações. São Paulo: Integrare Editora, 2012.

ROBBINS, Stephen P. Comportamento organizacional. 8. ed. Rio de Janeiro: LTC, 1999.

ROBBINS, Stephen P. JUDGE, Timothy A. Fundamentos do comportamento organizacional. 12. ed. São Paulo: Pearson Education do Brasil, 2014.

SOUZA, Carla Patrícia da Silva. Cultura e clima organizacional: compreendendo a essência das organizações. Curitiba: InterSaberes, 2014.

VELOSO, Elza Fátima Rosa. SILVA, Rodrigo Cunha da. DUTRA, Joel Souza. Gerações e Carreira: A Relação entre as Percepções sobre Carreiras Inteligentes e sobre Crescimento Profissional nas Organizações. XXXV Anais do EnAnpad. Rio de Janeiro: Anpad, 2011. Disponível em: <http:/ / www.progep.org.br/MelhoresEmpresas/ InfoDocs/GPR397\%20-\%20Rodrigo\%20-\%20Gera\%C3\%A7\%C3\%B5es $\% 20 \mathrm{e} \% 20$ Carreiras.pdf $>$. Acesso em: 22 jul. 2017.

VERGARA, Sylvia Constant. Projetos e relatórios de pesquisa em administração. 15. ed. São Paulo: Atlas, 2014. 